\title{
Surface Functionalization of Gold Nanorods Improves Nanostructure Assemblies on Amyloid Fibril Scaffolds
}

\author{
Mani Salimian, ${ }^{1}$ Tahereh Tohidi Moghadam ${ }^{2 \star}$ \\ and Bijan Ranjbar ${ }^{2,3}$ \\ ${ }^{1}$ Department of Biomaterials Engineering, Faculty of High Technologies, Tarbiat Modares University, Tehran, Iran \\ ${ }^{2}$ Department of Nanobiotechnology, Faculty of Biological Sciences, Tarbiat Modares University, Tehran, Iran \\ ${ }^{3}$ Department of Biophysics, Faculty of Biological Sciences, Tarbiat Modares University, Tehran, Iran \\ *Corresponding author: E-mail: t.tohidi@modares.ac.ir
}

Received: 07-30-2019

\begin{abstract}
A hybrid scaffold containing gold nanorods and lysozyme amyloid fibrils has been fabricated, and the effect of surface modification on improving nanostructure assembly on the biological template has been investigated. The nanohybrid system was characterized by monitoring surface plasmon resonance bands, dynamic light scattering spectroscopy, Thioflavin-T assay, and transmission electron microscopy. Surface of gold nanorods (GNRs) was modified with polystyrene sulfonate (PSS), and possible difference in assembly of the pristine and modified nanostructures was compared upon interaction with amyloid fibrils. Analysis of transmission electron microscopy showed that changing the surface charge of GNRs with biocompatible polymer improved electrostatic interactions between the nanostructures and amyloid fibril templates. Analysis of cell viability assays also showed that surface functionalization of GNRs remarkably improved biocompatibility of the nanoscaffold. Results of this study encourage utilization of modification strategies to fabricate a new generation of nanoscaffolds with fruitful applications in regenerative medicine.
\end{abstract}

Keywords: Gold Nanorods; Surface Plasmon Resonance; Nanoscaffold; Amyloid Fibrils

\section{Introduction}

Recent developments in nanotechnology have encouraged rapid development of variety of nanomaterials, including quantum dots, carbon nanotubes, plasmonic nanoparticles, etc., to resolve a wide range of medical, biological, catalytic, optical issues. Amongst different structures and materials at nanoscale, plasmonic nanoparticles with typical size in the range of $1-100 \mathrm{~nm}$ have received widespread attention due to showing enhanced optical, magnetic, electronic and structural properties. The distinct characteristics of such tiny particles mainly originate from interaction between conductive free electrons of the nanoparticles and the electromagnetic radiation. Surface plasmon is a collective electrons oscillation existing at metal-dielectric interface which responds quickly to the changes of environmental conditions. ${ }^{1}$ Such sensitivity to trace changes in the local refractive index, candidates plasmonic nanoparticles for variety of fruitful applications in nanomedicine and biosensing. ${ }^{2,3}$ Upon modifications in synthesis conditions, shape of gold nanoparticles could be directed to form anisotropic nanoparticles of rod morphology. Gold nanorods (GNRs) with unique ability to scatter light in the near infrared region have been nominated as promising theranostic agents for different biomedical applications, such as biomedical imaging, biosensing, drug delivery, cancer therapy, regenerative medicine etc. ${ }^{4,5}$

Taking the advantages and applications of plasmonic nanoparticles into consideration, fabrication of hybrid nanoscaffolds with simultaneous exploitation of the optical/ electronic properties of the nanoparticles, as well as the functional and structural characteristics of typical biological templates, provides new prospects for nanobiotechnology researchers. Recently, combination of nanoparticles with biomolecules of interest has motivated special attention. ${ }^{6,7}$ An interesting area of research currently involves arranging plasmonic nanoparticles on biological scaffolds with potential application in tissue engineering. ${ }^{8,9}$ The most important issues in tissue engineering is fabrication of structural component that simulates extracellular ma- 
trix (ECM) by providing a physical substrate for cellular adhesion, migration, division and transferring differentiation biochemical signals to cells. The biological scaffolds are constructed by several methods; such as self-assembly and thermally induced phase separation and electrospinning from natural proteins, polysaccharides, synthetic and inorganic materials. ${ }^{10}$ Self-assembly is an innate feature of some proteins in formation of nanofibers. ${ }^{11}$ Due to its advantages as a variety of manufacturing processes, low cost, simple and requires laboratory facilities and injectable form a three-dimensional structure, a suitable method to produce nano-scaffolding protein. In this regard, amyloid fibrils are a well-investigated example of self-assembled polypeptides and have been nominated as attractive candidates for applications in materials science and tissue engineering. ${ }^{11}$ Lysozyme amyloid fibers with high solubility, good mechanical and chemical strength and dimensions at nano scale are particularly attractive choice.

In previous studies, formation of lysozyme amyloid fibrils at low concentrations in an aqueous environment has been examined by using heat, low $\mathrm{pH}$, ionic elements and stirring. ${ }^{12,13}$

Herein, lysozyme amyloid fibril has been produced using self-assembly method under harsh environment, providing a natural/biological template for the hybrid scaffold. To monitor the efficiency of interaction with amyloid fibrils, assembly of pristine and PSS-modified plasmonic nanostructures of gold with rod morphology (GNRs) was monitored on the nanoscaffold. Formation of the amyloid fibril, anisotropic nanostructure, the surface charge and final nanoscaffold was characterized by UV-Visible, ThT assay, dynamic light scattering, and transmission electron microscopy.

\section{Experimental Section}

\section{1. Materials}

Gold (III) chloride trihydrate $\left(\mathrm{HAuCl}_{4}\right)(>99.9 \%)$, sodium borohydride $\left(\mathrm{NaBH}_{4}\right)(>99 \%)$, hexadecyltrimethylammonium bromide (CTAB) (>99\%), silver nitrate (>99\%), and L-Ascorbic acid (>98\%), Sodium phosphate, Polystyrene sulfonate (PSS), sodium hydroxide, hydrochloric acid and Hen egg white lysozyme (HEWL, >99\%) were procured from Sigma-Aldrich and used without further purification. All experiments were conducted by deionized water.

\section{2. Synthesis, Purification and Modification of Gold Nanorods}

2. 2. 1. Preparation of Au Seeds and Gold Nanorods

Gold nanorods were synthesized via sequential seed mediated growth method, as described previously. ${ }^{14}$ Briefly, small spherical gold nanoparticles (seeds) were prepared by mixing aqueous solutions of $\mathrm{HAuCl}_{4} \cdot 3 \mathrm{H}_{2} \mathrm{O}$
$(250 \mu \mathrm{L}, 0.01 \mathrm{M})$ and CTAB $(7.5 \mathrm{~mL}, 0.095 \mathrm{M})$, followed by immediate addition of ice-cold $\mathrm{NaBH}_{4}$ solution $(600 \mu \mathrm{L}$, $0.01 \mathrm{M})$. The reactants were mixed rapidly for two minutes and kept undisturbed at room temperature for a minimum of 2 hours. The growth solution was then prepared by sequential addition of CTAB $(9.5 \mathrm{~mL}, 0.095 \mathrm{M}), \mathrm{HAuCl}_{4}$. $3 \mathrm{H}_{2} \mathrm{O}(400 \mu \mathrm{L}, 0.01 \mathrm{M}), \mathrm{AgNO}_{3}(60 \mu \mathrm{L}, 0.01 \mathrm{M})$ and ascorbic acid $(64 \mu \mathrm{L} 0.10 \mathrm{M})$ solutions, followed by mixing with seed particles $(40 \mu \mathrm{L})$. It will take several hours for formation of rod-shaped nanostructures.

\section{2. 2. Purification of Gold Nanorods}

The excess cationic surfactant (CTAB) and unreacted gold were decanted by centrifugation process $(14,000$ $\mathrm{rpm}, 7 \mathrm{~min}$ ). The precipitate was diluted by distilled water and the purified sample was sonicated for several minutes to redisperse the nanorods.

\section{2. 3. Surface Modification of GNRs with PSS}

To induce electrostatic interaction between lysozyme fibrils and GNRs, surface of the purified nanostructures was coated by PSS polymer. Working solutions of $1.5 \mu \mathrm{M}$ and $5 \mu \mathrm{M}$ PSS were treated with GNRs and the mixture was stirred $(100 \mathrm{rpm})$ at room temperature for 4 hours. Concentration range of the polymer with respect to GNRs was optimized by monitoring the characteristic surface plasmon resonance of the nanostructures upon interaction with PSS. This minimizes the possibility of unwanted aggregation of GNRs at higher concentrations of polymer solution. Excess PSS was removed by centrifugation at $12500 \mathrm{rpm}$, and total volume of the PSS-modified GNR solution was adjusted to $1 \mathrm{ml}$.

\section{3. Synthesis of Lysozyme Amyloid Fibrils}

A stock solution containing $2.5 \mathrm{mg} \mathrm{mL}^{-1}$ lysozyme was prepared and adjusted to $\mathrm{pH} 1.6$, using $\mathrm{HCl}$. The solution was then incubated at $65^{\circ} \mathrm{C}$ for $9 \mathrm{~h}$ with continuous agitation by a stirrer.

\section{4. Preparation of the Hybrid Nanoscaffold}

Two series of pristine and PSS-modified GNRs were prepared for interaction with amyloid fibrils. The hybrid nanoscaffold consisting of GNRs and the biological template was prepared by treating $5 \mu \mathrm{L}$ of amyloid fibrils (diluted with $285 \mathrm{~mL}$ of deionized water) with $700 \mu \mathrm{L}$ of GNRs (OD 1). The mixture was incubated for 4 hours.

\subsection{Characterization Techniques}

\section{5. 1. Surface Plasmon Resonance of GNRs}

To verify the rod morphology of plasmonic nanoparticles the characteristic surface plasmon resonance (SPR) 
of GNRs was monitored using UV-Visible spectrophotometer. SPR spectra of both pristine and PSS-modified GNRs were recorded on a Perkin Elmer in the wavelength region of 400-900 nm.

\section{5. 2. Zeta Potential Analysis of PSS-Modified GNRs}

Zeta potential of the purified GNRs before and after modification with PSS was recorded using Malvern Zetasizer. Prior to analysis, samples were filtered and sonicated for proper dispersion of the nanostructures.

\section{5. 3. Thioflavin $T$ (ThT) Fluorescence Assay}

Kinetics of amyloid fibril formation was studied using ThT assay. During amyloid fibrillation, sampling was carried out each 1h. $20 \mu \mathrm{L}$ ThT solution $(250 \mu \mathrm{M})$ was incubated with $80 \mu \mathrm{L}$ of protein samples. ThT fluorescence was monitored using a spectrofluorimeter (FP-6500; Jasco) with $5 \mathrm{~nm}$ slit-width. Intensity of fluorescence was recorded by exciting at $440 \mathrm{~nm}$ and recording the emission at $485 \mathrm{~nm}$, at room temperature.

\section{5. 4. Transmission Electron Microscopy of the Hybrid Scaffold}

GNRs micrographs were taken by transmission electron microscopy (TEM) (Philips CM200-FEG, USA. Assembly of pristine and PSS-modified GNRs on the amyloid fibril template was imaged, by drop casing $5 \mu \mathrm{L}$ of each sample on carbon coated copper grid.

\section{6. Cell Culture and Cell Viability Assay}

The HepG2 and fibroblast cells were cultured in DMEM medium supplemented with $1 \%(\mathrm{v} / \mathrm{v})$ penicillin-streptomycin and $10 \%(\mathrm{v} / \mathrm{v})$ heat inactivated FBS. Cells were maintained in $5 \% \mathrm{CO}_{2}$ humidified incubator at $37^{\circ} \mathrm{C}$. During subculture, cells were detached by trypsinization when they reached $90 \%$ confluency. The cells were harvested and seeded into 96- well plates at a density of 10000 cells per well for experiments.

MTT assay measures the reduction of a tetrazolium component into an insoluble formazan product by the mitochondria of viable cells. The insoluble dye formed in MTT assay was solubilized using DMSO. Cells were seeded in 96-well tissue culture plates $(10000$ cell/well in $100 \mu \mathrm{L}$ DMEM culture medium) and incubated overnight at $37^{\circ} \mathrm{C}$ and $5 \% \mathrm{CO}_{2}$. Morphology of cells was then observed by an invert microscope before exposure to Gold nanorods. After overnight growth, $15 \mu \mathrm{L}$ of samples containing bare GNRs, GNRs-PSS, bare Amyloid fibrils, GNRs-Amyloid fibrils and GNRs-PSS-Amyloid fibrils were diluted with deionized water to make $0,1,2.5,5$, $10,15,25 \mathrm{nM}$ of the nanostructures. Samples were ex- posed to HepG2 and fibroblast cell lines in each well of 96-well tissue culture plates. Treated cells were incubated for 24 and 48 hour at $37^{\circ} \mathrm{C}$ and $5 \% \mathrm{CO}_{2}$. Morphology of cells was observed by invert microscope after exposure to different concentrations of nanostructures. After 24 and 48 hours, $10 \mu \mathrm{L}$ MTT solution (50 mg/10 mL PBS) was added to each well and the plates were incubated for $4 \mathrm{~h}$. Supernatants were replaced by $100 \mu \mathrm{L}$ DMSO and samples were analysed by an ELISA plate reader at $570 \mathrm{~nm}$. All absorbance values were corrected against blank wells containing growth media. Each assay was done in triplicate and mean \pm standard deviation values were calculated.

\section{Results and Discussion}

\section{1. Characterization of the Anisotropic Nanostructures}

\section{1. 1. Surface Plasmon Resonance and Transmission Electron Microscopy}

Surface plasmon resonance bands of gold nanorods were monitored in the visible and near infrared region, representing oscillation of the conduction band electrons along the short and long axis of GNRs (Fig. 1). Appearance of the strong longitudinal surface plasmon resonance band (LSPR) at $750 \mathrm{~nm}$, along with transverse SPR band of weaker intensity at $531 \mathrm{~nm}$ is characteristic of formation of nanostructure with rod morphology. While transverse surface resonance band normally does not show any particular changes upon changes in the refractive index, the longitudinal one (LSPR) shows significant sensitivity to trace changes in the local environment. ${ }^{3}$ Such response to changes has been exploited in designing novel plasmonic theranostic agents, as well as monitoring biomolecular interactions and molecular binding events.

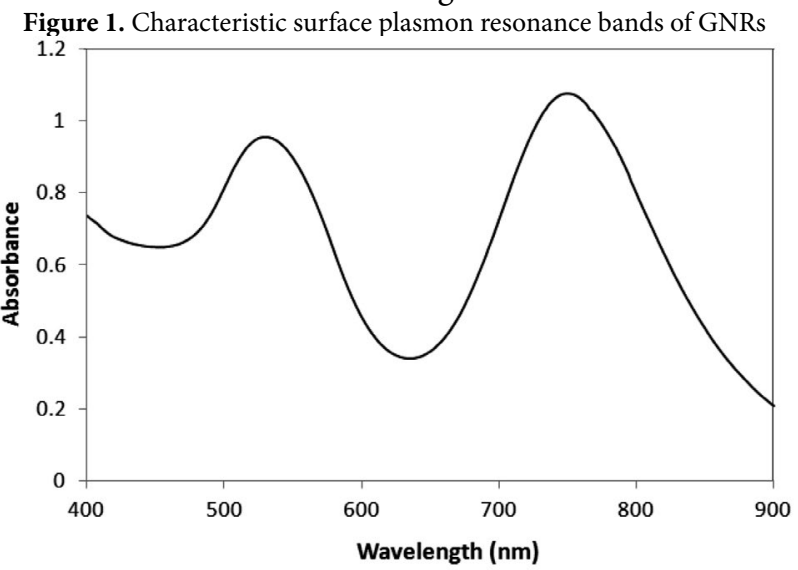

Transmission electron microscopy (TEM) image of the purified samples also confirmed formation of the anisotropic nanostructures with rod morphology. Given 


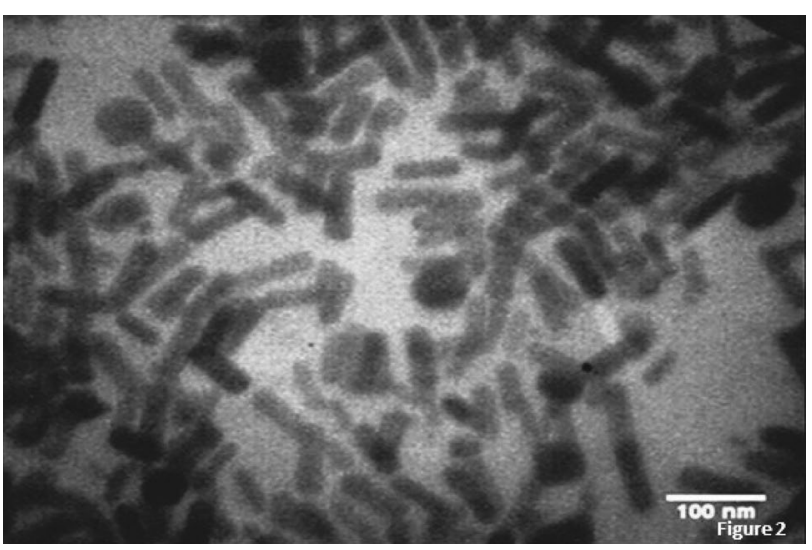

Figure 2. Transmission electron microscopy image of GNRs

the average dimensions by TEM, the mean aspect ratio of GNRs was calculated to be $3.8 \pm 0.3$ (Fig. 2.)

\section{1. 2. Surface Modification of Gold Nanorods}

The position of the SPR peaks, the absorbance intensity and the peaks heights relative to each other are associated with the particle size, population of nanostructures and their aspect ratio, respectively. ${ }^{15}$ Surface of GNRs provide a convenient matrix for interaction and/or conjugation with molecules of interest, for various chemical, physical and biological applications. Any changes at nanoparticle interface can be studied by tracing its characteristic SPR spectra in the visible and near infrared region. In this study, surface of GNRs were modified with polystyrene sulfonate (PSS), to reverse the surface charge of the nanostructures and provide opportunity for electrostatic interactions with amyloid fibrils, as well as increasing biocompatibility of the final nanoscaffold for future investigations in tissue engineering.

Upon increasing the PSS concentration (above 5 $\mu \mathrm{M}$ in this investigation), macroscopic aggregates were noticed in GNR samples. This could be attributed to perturbations in morphology of the nanostructure, losing the typical rod shape. To ensure that anisotropy of GNRs is maintained, SPR spectra were monitored in the presence of PSS with different concentrations. Fig. 3a depicts transverse and longitudinal SPR bands of GNRs upon interaction with two selected concentrations of polymer (PSS), i.e. 1.5 and $5 \mu \mathrm{M}$ of polymer. In the presence of polymer solution, the nanostructures showed redshift in the position, as well as decrease in the intensity of longitudinal SPR. This could be attributed to modification of GNRs' surface with PSS. Although the two counterparts provide opposite surface charge, the characteristic SPR of GNRs has not been perturbed, representing electrostatic interactions, while maintaining the rod morphology within the specified range of polymer concentration. Further experiments, i.e. assembling of PSS-modified GNRs on the biological template were carried out using

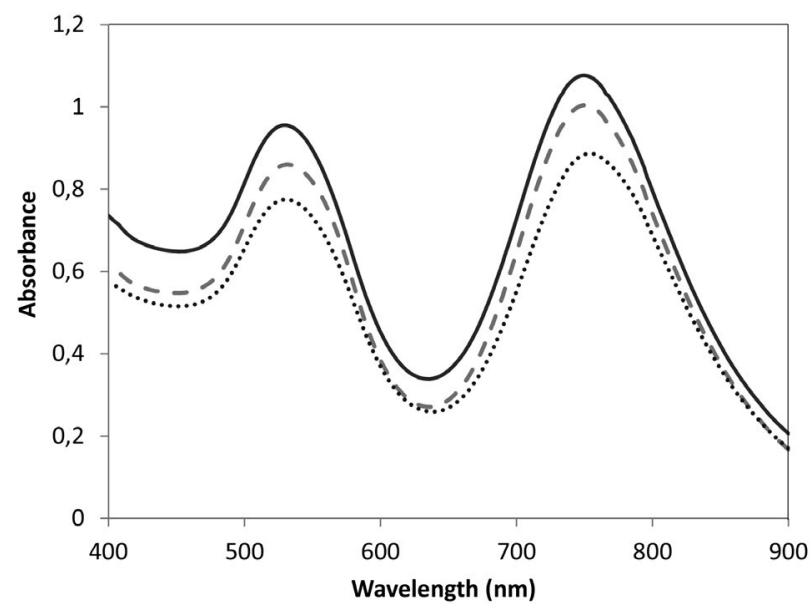

Figure 3. Changes in the SPR bands of GNRs after modification with PSS. From top to bottom: control GNRs, GNRs-PSS $(1.5 \mu \mathrm{M})$, and GNRs-PSS $(5 \mu \mathrm{M})$.

$5 \mu \mathrm{g} / \mathrm{ml}$ PSS.

To confirm change in the surface charge of GNRs, dynamic light scattering (DLS) spectroscopy was used. This technique provides useful information about some parameters, including particle size distribution, molecular weight and zeta potential. ${ }^{15}$ Fig. 4 depicts zeta potential analysis of GNRs, before and after modification with PSS. Surface of pristine GNRs shows highly positive charge due to presence of cationic surfactant (CTAB), as one of the key chemicals in dictating anisotropy in the nanostructure. Although several rounds of centrifugation are conventionally used to remove excess CTAB molecule from the medium, it still exist after purification processes. Therefore, presence of CTAB provides net positive charge for GNRs. Upon interaction of GNRs with PSS, cationic CTAB is replaced by polymer molecule, reversing the net charge of GNRs from +48 $\mathrm{mV}$ to $-38 \mathrm{mV}$.

\section{2. Characterization of the Biotemplate and}

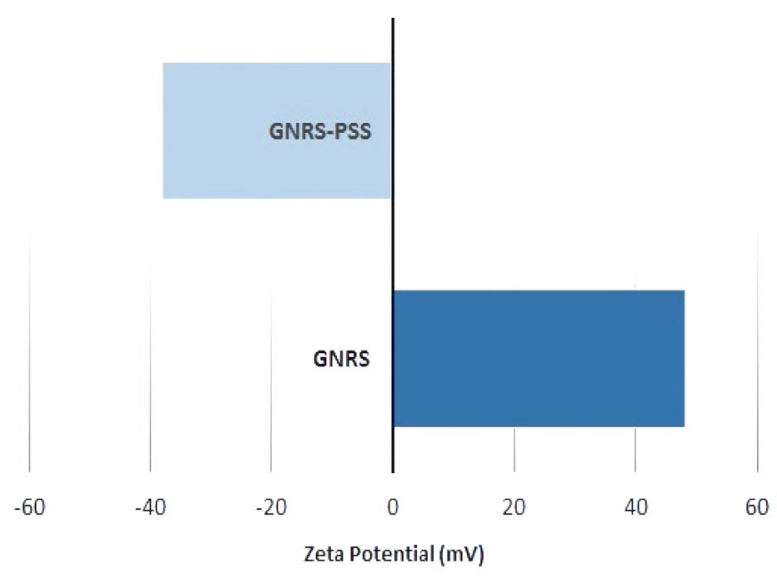

Figure 4. Analysis of zeta potential for pristine and PSS-coated GNRs 


\section{the Hybrid Scaffold}

\section{2. 1. Thioflavin $T$ (ThT) Fluorescence Assay}

To investigate the kinetics of amyloid fibrils formation, Thioflavin T (ThT) Fluorescence assay was used. This method is highly specific and quantitative technique that can clearly show changes in the protein secondary structures. Treated samples were kept away from light for about 5 minutes at room temperature. As shown in Figure 5, intensity of fluorescence emission increased upon formation of $\beta$-sheet structures. The increasing trend reaches a plateau upon completion of amyloid formation (data not shown).

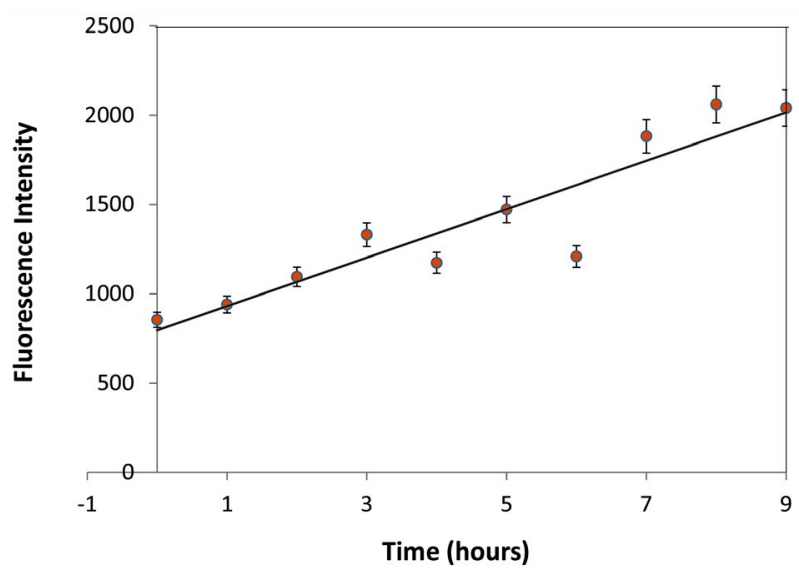

Figure 5. Thioflavin-T Assay of lysozyme upon transformation into amyloid fibril structures

\section{2. 2. Transmission Electron Microscopy of the Hybrid Scaffold}

To study possible role of nanostructure surface modification in improving yield of assembly on the biological template, two samples of pristine and PSS-coated GNRs were compared. Fig. 6 depicts transmission electron microscopy images of lysozyme amyloid fibrils treated with

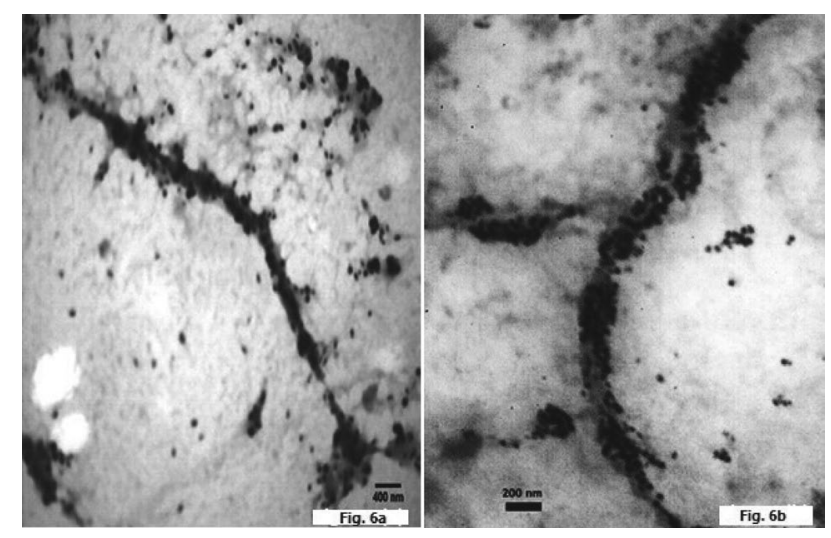

Figure 6. Transmission electron microscopy of plasmonic gold nanoparticle arrays on lysozyme amyloid fibrils, with pristine (a) and PSS-modified (b) plasmonic nanostructures. pristine and PSS-modified nanostructures. Fig. 6b shows that surface modified plasmonic nanostructures with opposite electrostatic charge have more tendencies to interact with the biological template, as compared to their pristine counterpart (Fig. 6a). Taking the positive zeta potential value of lysozyme amyloid fibrils into consideration, the biotemplate provided opposite electrostatic charge for better interaction with the surface modified GNRs. Assembly of higher population of nanostructures via such strategy could facile fabrication of nanohybrid scaffold of more uniformity.

\section{3. Cell Viability Results}

Viability percentage measured by MTT assay on HepG2 and fibroblast cell lines exposed to $0,1,2.5,5$, $10,15,25 \mathrm{nM}$ GNRs in samples containing bare GNRs, GNRs-PSS, bare Amyloid fibrils, GNRs-Amyloid fibrils and GNRs-PSS-Amyloid fibrils for 24 and $48 \mathrm{~h}$ represented a dose response pattern as shown in Figs. 7 and 8. Data were reported as mean \pm SD of three independent experiments performed in triplicate for all samples.

As expected from MTT assay results, intact GNRs were severely toxic at higher concentrations, i.e. $25 \mathrm{nM}$. This due to the fact that the nanostructures are synthesized in the presence of high concentrations of cationic surfactant (CTAB). Although GNRs are purified with several rounds of centrifugation, there still exists the bilayer of CTAB around the bare nanostructures. Upon replacing the cationic bilayer with PSS, cells exposed to GNRs-PSS showed less toxicity as compared to the bare nanostructures. Meanwhile, a glance at cell viability data for the hybrid systems (the nanoscaffolds) shows that PSS-coated GNRs arrays on lysozyme amyloid fibrils have manifested a higher percentage of viability in comparison with the nanoscaffolds containing bare GNRs arrays on amyloid fibrils. Overall, GNRs-PSS and GNRs-PSS-Amyloid fibrils depicted high cell survival at lower concentrations of the nanostructures, with less toxicity at higher concentrations for both cell lines.

Developing biodegradable scaffolds by self-assembly method based on DNA, protein and virus capsid is progressing every day. ${ }^{16,17}$ For example, to support nervous cell regeneration, nanoscaffolds have played an important role in stem cell therapy and brain reconstruction. In this regard, Cass et al. designed bioresponsive nanoscaffolds using engineered self-assembling peptides to connect and grow nervous stem cells. ${ }^{17}$

Tissue engineering has great potential to develop and modify patches, meshes, and cell sheets of more similarity to the host tissue. For this reason, bio-based hydrogel are known as suitable options for repairing and reconstructing cardiac cells.

Today, abundant natural and synthesized hydrogels, such as collagen, gelatin, matrigel and PNIPAA are utilized to replace the damaged parts in cardiac muscle. ${ }^{18-21}$ 
a)

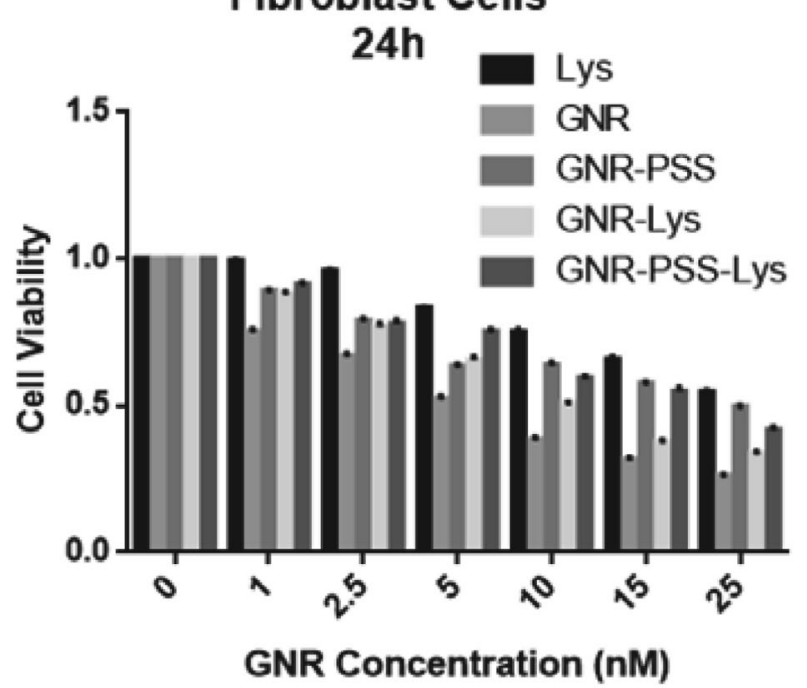

b)
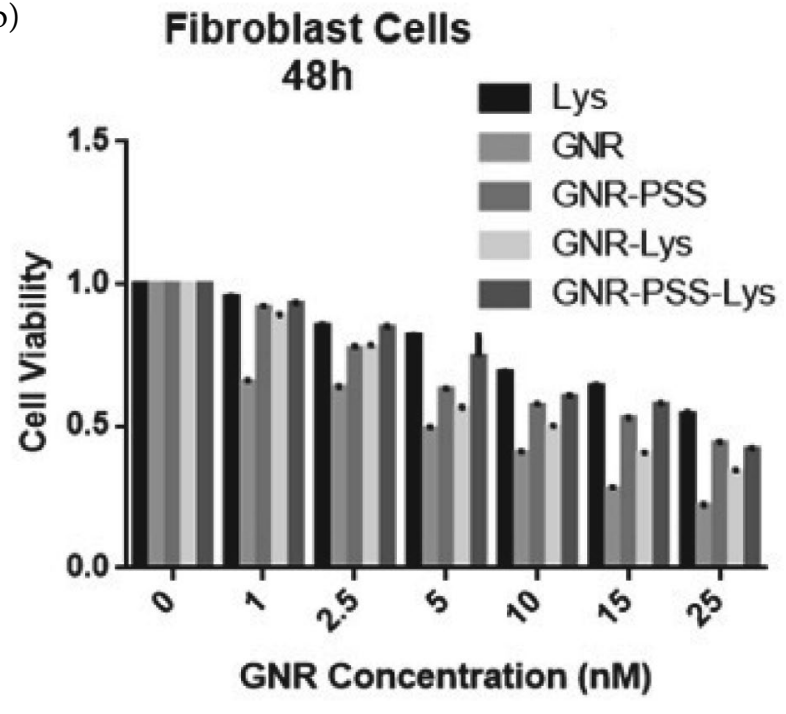

Figure 7. Cell viability assay for fibroblast cell line incubated for $24 \mathrm{~h}$ (a) and $48 \mathrm{~h}$ (b) with Lys, GNRs, GNRs-PSS, GNRs-Lys and GNRs-PSS-Lys. The abbreviation Lys represents Lysozyme Amyloid Fibrils.

a)

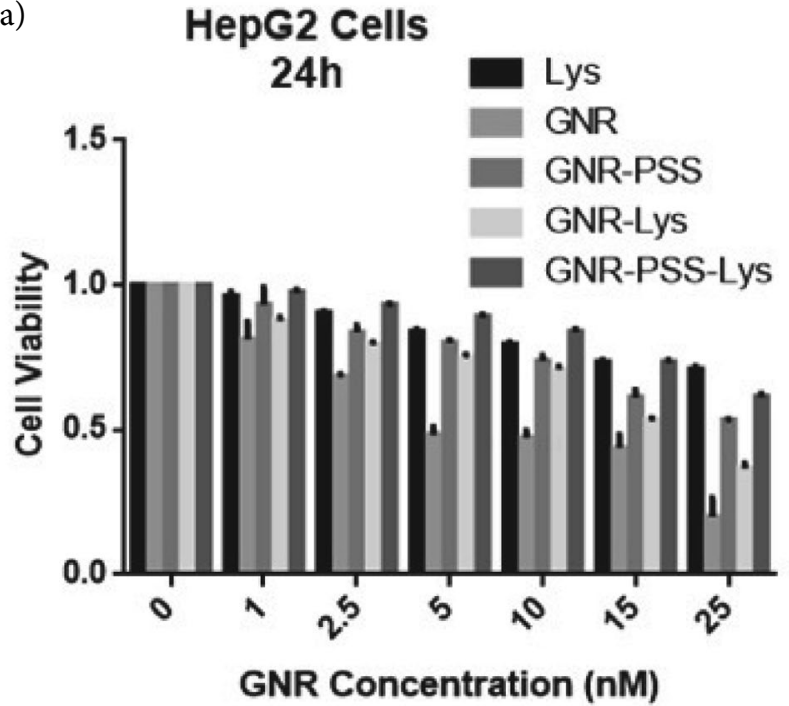

b)
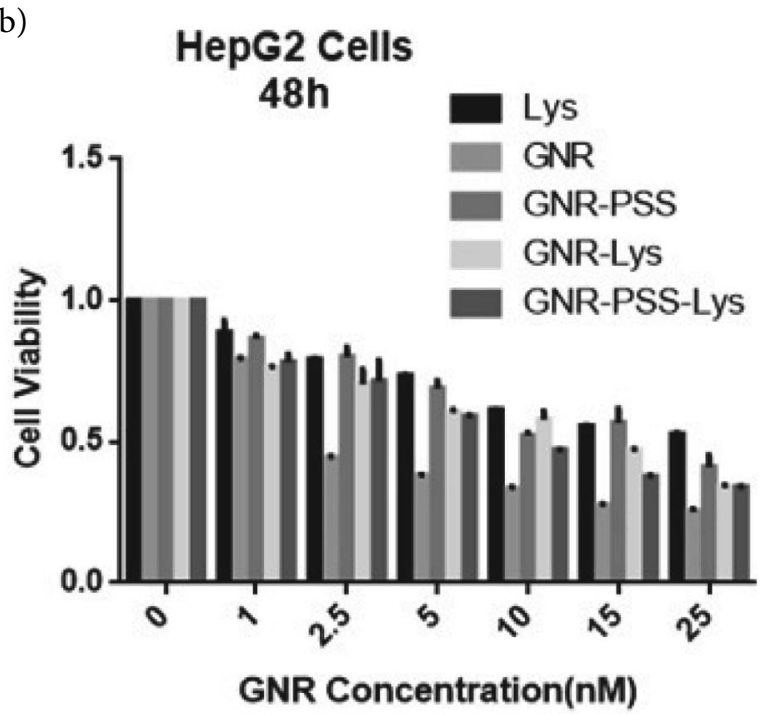

Figure 8. Cell viability assay for HepG2 cell line incubated for $24 \mathrm{~h}$ (a) and $48 \mathrm{~h}$ (b) with Lys, GNRs, GNRs-PSS, GNRs-Lys and GNRs-PSS-Lys. The abbreviation Lys represents Lysozyme Amyloid Fibrils.

Although hydrogels provide micron-like space similar to ECM to support cardiac function, their electrical conductivity is not very efficient. Especially, the presence of electrical insulations in these hydrogel structures, causes poor cardiac binding and consequently, poor performance in tissue engineering. ${ }^{22}$ To overcome this issue, nanostructures of good conductivity can be employed. Carbon nanotubes are known to provide electrical conductivity and proper inter-cellular communication. Nevertheless, their tendency to form accumulations on tissue surfaces induces cellular toxicity, which has raised serious concerns about their medical applications. ${ }^{23,24}$ In this regard, coat- ings and functionalization of nanotubes have been proposed to reduce cell toxicity. However, these changes are expected to affect electrical properties. In addition, insolubility of CNTs in aqueous systems has made it unfavorable to utilize in biological systems. Therefore, replacing CNTs with plasmonic gold nanostructures can be a better idea to overcome toxicity problems in biomedical applications. Plasmonic nanostructures can be produced with various morphologies, e.g. sphericals, rods, prisms, cubes, etc. with promising applications in biomedicine and biosensing. High electrical conductivity, low toxicity, facile synthesis, ease of functionalization and low cost of production 
at large scale can be considered as their advantages over other nanoparticles. Amongst gold nanoparticles, gold nanorods have shown remarkable features in biosensing platforms, especially when compared to spherical nanoparticles. The great sensitivity of these rod shaped gold nanostructures to trace changes in the local environment enables their utilization in hybrid scaffolds with superior sensitivity and conductivity.

There are a number of reports on the use of gold nanoparticles in tissue scaffolds, which include several polymers, such as alginate, poly L-caprolactone, Poly (thiol-HEMA) and decellularized omental matrix, showing the potential of these nanoparticles for utilization in conductive scaffolds. ${ }^{24-26}$

Enhancement in the catalytic activity can also be considered as one of the important and key features of gold nanoparticles due to providing high specific surface area. Mishra et al. reported fabrication of AuFeAg hybrid nanoparticles as an efficient recyclable system with catalytic function. The hybrid nanocatalyst exhibited catalytic activity for the synthesis of $\alpha, \beta$ - and $\beta, \beta$-dichloroenones, which are important synthetic intermediates in the preparation of natural products. ${ }^{27}$

Specific features such as electrical conductivity, mechanical strength, and structural integrity are required to improve the function of the cardiac cells. In a recent study, the role of embedded gold nanoparticles in methacrylate gel was shown to improve electrical conductivity and stiffness of the matrix. ${ }^{8}$ The cardiac cells implanted in the matrix have demonstrated the ability to survive and maintain their metabolic function. The uniform dispersion of the specific markers of the cardiac cells confirmed the effect of the nanoparticles concentration.

Researchers at MIT have recently reported fabrication of cardiac patches decorated with tiny gold wires that could be used to create pieces of tissue whose cells all beat in time, mimicking the dynamics of natural heart muscle. ${ }^{28}$ They used alginate as the base material that is often used for tissue scaffolds and combined it (randomly) with gold nanoparticles. In this study, conduction of the previously designed tissues of pure alginate was compared with its composite scaffold. Combination of alginate and gold nanoparticles provided significant enhancement in signal conduction, i.e. a few hundred micrometers with respect to a scale of millimeters. This idea could notably pave the way for designing conductive systems in muscle cells and vascular constructs as well as neural systems, showing a significant impact on the collective communication of cells. Nevertheless, we believe that assembly of gold nanostructures of rod morphology on fibrillar templates with biological origin might be a better option for such applications. Our group has recently reported synthesis and characterization of assembled gold nanorods on HSA amyloid fibrils. ${ }^{29}$ Therefore, the fibrillar biotemplate with evidenced mechanical and chemical stability can properly compensate the fibrillar pattern of CNTs and assembly of
GNRs can retrieve its conductivity.

In line with this study, the present effort aimed to improve the interaction and assembly of GNRs on Lysozyme amyloid fibrils via surface functionalization of the nanostructures with polystyrene acetate. Apart from formation of a hybrid nanoscaffold with improved interaction between the nanostructures and the biological template, PSS coating of GNRs can play a significant role in ensuring biocompatibility of the nanostructures, due to the replacement of the cationic surfactant (CTAB) by the biocompatible polymer.

Taking the previous achievements into consideration, the idea of assembling rod-shaped gold nanostructures on biological templates is worth to investigate due to the possibility of developing a new generation of hybrid nanoscaffolds with lower toxicity, promising fruitful applications in various sensing platforms, tissue engineering and regenerative medicine.

\section{Conclusion}

This effort has focused on fabrication of a nanohybrid scaffold through combination of amyloid fibrils as biotemplates, and plasmonic nanostructures of gold with rod morphology. Amyloid fibrils of lysozyme provided a surface for assembly of gold nanostructures. Gold nanorods were interacted with biotemplates in two different forms of pristine and polymer coated nanostructures. Surface modification of GNRs with biocompatible polymer (PSS) improved electrostatic interactions between the nanostructures and amyloid fibril templates, and facilitated assembly of more GNRs on the biotemplate. Cell viability assays also confirmed an increase of biocompatibility for the nanoscaffold upon surface coating with PSS. Such a modification strategy could pave the way for fabrication of hybrid nanoscaffolds of more uniformity, providing a better chance to produce a new generation of hybrid materials with fruitful applications in biosensing and regenerative medicine.

\section{Declarations}

- Availability of data and material

All raw and analyzed data as well as the materials are available in this study.

- Competing interests

The authors do not have any competing interests.

- Funding

The financial grant for chemicals and characterization facilities has been provided by Tarbiat Modares University.

- Authors' contributions

Mani Salimian conducted the experiments, analyzed data and wrote some parts of the manuscript.

Tahereh Tohidi Moghadam designed the experiments, 
supervised the project and wrote some parts of the manuscript.

Bijan Ranjbar advised on analysis and interpretation of data.

- Acknowledgements

The authors would like to acknowledge Tarbiat Modars Univrsity for providing characterization facilities.

\section{References}

1. S. Guo, E. Wang, Nano Today 2011, 6, 240-264.

DOI:10.1016/j.nantod.2011.04.007

2. T. Tohidi Moghadam, B. Ranjbar, Int. J. Biol. Macromol. 2015, 51, 91-96. DOI:10.1016/j.ijbiomac.2012.04.020

3. S. Shams, B. Bakhshi, J. Nanobiotechnology 2019, 17, 1-13. DOI:10.1186/s12951-019-0476-0

4. Y. Ma, HX. Xia, YP. Liu, B. Liu, W. Chen, Chinese Sci. Bull. 2013, 58, 2530-2536. DOI:10.1007/s11434-013-5720-7

5. M. K. Popp, I. Oubou, C. Shepherd, Z. Nager, C. Anderson, L. Pagliaro, J. Nanomater 2014, 1-8. DOI:10.1155/2014/450670

6. W. R. Algar, D. E. Prasuhn, M. H. Stewart, Bioconjugate Chem. 2011, 22, 825-858. DOI:10.1021/bc200065z

7. S. Ashrafpour, T. Tohidi Moghadam, Surfaces and Interfaces 2018, 10, 216-221. DOI:10.1016/j.surfin.2017.09.010

8. A. Navaei, H. Saini, W. Christenson, R. T. Sullivan, R. Ros, Acta Biomater. 2016, 41, 133-46.

DOI:10.1016/j.actbio.2016.05.027

9. A. Ito, Y. Takizawa, H. Honda, K. Hata, H. Kagami, Tissue Eng. 2004, 10, 833-840. DOI:10.1089/1076327041348301

10. B. Dhandayuthapani, Y. Yoshida, T. Maekawa, Int. J. Polym. Sci. 2011, 1-19. DOI:10.1155/2011/290602

11. O. Deschaume, B. De Roo, MJ. Van Bael, Chem. Mater. 2014, 26, 5383-5393. DOI:10.1021/cm502652t

12. S. Y. Ow, D. E. Dunstan, Soft Matter 2013, 9, 9692-9701.
DOI: $10.1039 / \mathrm{c} 3 \mathrm{sm} 51671 \mathrm{~g}$

13. E. Takai, G. Ohashi, R. Ueki, Y. Yamada, Am. J. Biochem. Biotechnol. 2014, 10, 31-39. DOI:10.3844/ajbbsp.2014.31.39

14. T. Tohidi Moghadam, B Ranjbar, K. Khajeh, Int. J. Biol. Macromol 2012, 49, 629-636.

DOI:10.1016/j.ijbiomac.2011.06.021

15. M. A. Mahmoud, M. A. El-Sayed, J. Am. Chem. Soc. 2010, 132, 12704-12710. DOI:10.1021/ja104532z

16. H. Kitching, M. J. Shiers, A. J. Kenyon, J. Mater. Chem. A 2013, 1, 6985-6999. DOI:10.1039/c3ta00089c

17. T. Scheibel, R. Parthasarathy, Proc Natl, Acad. Sci. 2003, 100, 4527-4532. DOI:10.1073/pnas.0431081100

18. S Pedron, S Van Lierop, P Horstman, Adv. Funct. Mater. 2011, 21, 1624-1630. DOI:10.1002/adfm.201002708

19. H. Saini, A. Navaei, A. Van Putten, Adv. Healthc. Mater. 2015, 4, 1961-1971. DOI:10.1002/adhm.201500331

20. S. Khalil, W. Sun, J Biomech. Eng. 2009, 131, 1-8. DOI:10.1115/1.3128729

21. M. Radisic, H. Park, H. Shing, T. Consi, Proc. Natl. Acad. Sci. 2004, 101, 18129-18134. DOI:10.1073/pnas.0407817101

22. J. Zhou, J. Chen, H. Sun, X. Qiu, Y. Mou, Z. Liu, Y. Zhao, Sci. Rep. 2014, 4, 1-11. DOI:10.1038/srep03733

23. M. Kharaziha, SR. Shin, M. Nikkhah, SN. Topkaya, Sci. Rep. 2014, 4,7346-7354. DOI:10.1016/j.biomaterials.2014.05.014

24. H. Dumortier, Adv. Drug Deliv. Rev. 2013, 65, 2120-2126. DOI:10.1016/j.addr.2013.09.005

25. S. Fleischer, M. Shevach, R. Feiner, T. Dvir, Nanoscale 2014, 6, 9410-9414. DOI:10.1039/C4NR00300D

26. M. Shevach, R. Zax, A. Abrahamov, S. Fleischer, Biomed. Mater. 2015, 10, 34106. DOI:10.1088/1748-6041/10/3/034106

27. K. Mishra, N. Basavegowda, Y. R Lee, Appl. Catal. A Gen. 2015, 506, 180-187. DOI:10.1016/j.apcata.2015.09.014

28. T. Dvir, B. P. Timko, M. D. Brigham, SR. Naik, Nat. Nanotechnol., 2015, 6, 720-725. DOI:10.1038/nnano.2011.160

29. R. A. Taheri, Y. Akhtari, T. Tohidi Moghadam, B. Ranjbar, Sci. Rep. 2018, 8, 1-10. DOI:10.1038/s41598-018-26393-6

\section{Povzetek}

$\mathrm{Na}$ biološkem nosilcu iz amiloidnih vlaken lizocima smo pripravili podlago za nanos nanodelcev zlata ("gold nanorods« (GNR)). Za preučevanje tega sistema smo uporabili površinsko plazmonsko resonanco, flurescenčno spektroskopijo s tioflavinom T in presevno elektronsko mikroskopijo (TEM). Površino nanodelcev zlata (GNR) smo modificirali s polistirenskim sulfonatom (PSS). Preučevali smo razlike v interakcijah amiloidnih vlaken z nanodelci zlata, bodisi modificiranimi ali nemodificiranimi. Analiza s presevno elektronsko mikroskopijo (TEM) je pokazala, da je površinski naboj GNR z biokompatibilnim polimerom izboljšal elektrostatske interakcije med nanodelci zlata in amiloidnimi fibrili. Analiza opravljena s testi za določanje preživetja celic pa je pokazala, da je površinska funkcionalizacija GNR izjemno izboljšala biokompatibilnost nano kompozita. Rezultati te študije spodbujajo uporabo novih strategij za pripravo prihodnjih generacij materialov, ki bi jih lahko uporabili v medicini.

Except when otherwise noted, articles in this journal are published under the terms and conditions of the Creative Commons Attribution 4.0 International License 